\title{
Determination of the changes in the process of degradation of some pesticides applied in mixtures with plant growth regulators, foliar fertilizers and spreader-stricker in a vineyard ${ }^{1}$
}

\author{
Bağda bitki gelişim düzenleyicisi, yaprak gübresi ve yayıcı-yapıştırıcılarla karıştırılarak \\ uygulanan bazı pestisitlerin parçalanma sürecindeki değişimlerin belirlenmesi \\ Gülçin Pınar ÖRNEK ${ }^{\star}$ \\ Enver DURMUŞOĞLU³
}

\begin{abstract}
The study conducted in 2015-2016 examined effects of plant growth regulators (PGR), foliar fertilizers (FF) and spreader-sticker (SS) on the process of degradation of pesticides. First physical then chromatographic analyses were conducted in laboratory to determine whether degradation occurred even in spray tanks. In order to determine if changes occurred during the process of decomposition of pesticides in mixtures under field conditions, two experiments were set up in Izmir during the shooting and fruiting of grapevines in 2016. In shooting period, a mixture of azoxystrobin, imidacloprid and metalaxyl was blended with PGR, FF and SS in double and triple combinations to create eight treatments applied to three replicates to determine the process of degradation of active ingredients on leaf samples collected at given intervals. In general, it was observed that degradation of azoxystrobin, imidacloprid and metalaxyl on leaves applied with PGR, FF and SS was slower and the residues did not drop below maximum residue limits even after the preharvest interval. During the fruiting period, a mixture of boscalid, chlorpyrifos ethyl and hexythiazox was applied in the same way as for the shooting period. All mixtures with PGR, FF and SS tended to increase degradation of boscalid, but had no effect on the degradation on chlorpyrifos ethyl and hexythiazox.
\end{abstract}

Keywords: Foliar fertilizer, pesticide, plant growth regulator, preharvest interval, spreader-sticker, tank mix

$$
\text { Öz }
$$

2015-2016 yıllarında yürütülen bu çalışmada, asma yapraklarını toplama ve üzüm hasadı öncesi dönemlerde kullanılan bazı pestisitler ile bitki gelişim düzenleyicisi (BGD), yaprak gübresi (YG) ve yayıcı-yapıştırıcıların (YY) pestisitlerin parçalanma sürecine etkisi araştırımıştır. Bağda karışım halinde kullanılan pestisitlerin, ilaçlama alet deposunda parçalanma olup olmadığının belirlenmesi amacıyla laboratuvarda gerçekleştirilen önce fiziksel sonra da kromatografik analizlerde gerek pestisitlerin birbirleriyle gerekse diğer preparatlar ile karışımlarında herhangi bir önemli etkileşim görülmemiştir. Karışım halinde kullanılan pestisitlerin arazi koşullarında parçalanma sürecinde değişim olup olmadığını belirlemek üzere 2016 yılında İzmir'in Kemalpaşa ilçesindeki bir bağda iki farklı dönemde iki deneme kurulmuştur. Asmanın yaprak toplama döneminde azoxystrobin, imidacloprid ve metalaxyl içeren preparatların üçlü karışımı BGD, YG ve YY ile tekli, ikili ve üçlü olarak karıştıılarak 8 karakterli bir deneme üç tekerrürlü olarak uygulanmış, amaca uygun aralıklarla alınan yaprak örneklerinde aktif maddelerin degredasyon süreci belirlenmiştir. Genel olarak çoğu karışımlarda degredasyonunun yavaşladığı, bekleme süresi sonunda bile kalıntı miktarının MRL'nin altına düşürmediği görülmüştür. Üzüm döneminde ise boscalid, chlorpyrifos ethyl ve hexythiazox içeren preparatların üçlü karışımı, aynı asma yaprak döneminde olduğu gibi uygulanmıştır. Bu dönemde kullanılan tüm karışımlar, boscalidin degredasyon sürecini uzatmış, chlorpyrifos ethyl ve hexythiazoxun degredasyon sürecinde ise önemli bir etki görülmemiştir.

Anahtar sözcükler: Yaprak gübresi, pestisit, bitki gelişim düzenleyicisi, bekleme süresi, yayıcı-yapıştıııı, tank karışımı

\footnotetext{
${ }^{1}$ This article represents part of the Doctoral project of first author.

2 Izmir Food Control Laboratory Directorate, 35100, İzmir, Turkey

${ }^{3}$ Ege University, Faculty of Agriculture, Department of Plant Protection, 35100, Izmir, Turkey

* Corresponding author (Sorumlu yazar). e-mail: gulcinpinar.ornek@gthb.gov.tr

Received (Alınış): 27.03.2018Ａccepted (Kabul ediliş): 19.05.2018Ｐublished Online (Çevrimiçi Yayın Tarihi): 16.07.2018
} 


\section{Introduction}

A total of $65 \mathrm{Mt}$ of grapes from 7.5 Mha are produced in the world every year, of which Turkey produces 3.7 Mt from 0.46 Mha. Viticulture has a long history in Turkey dating back to antiquity as well as being a centre of genetic diversity of grapevines (Anonymous, 2014; TUIK, 2015). Given that there are numerous pests affecting grapevines, control of vineyard pests is vital. Although a great variety of control methods exist, it is chemical control that is most widely and effectively used as it achieves rapid, high level control (Durmuşoğlu et al., 2010). In the Aegean Region of Turkey, there are numerous sprays applied to grapevines to control diseases and pests during different phenological periods. Copçu et al. (2002) reported that about 27 different chemical sprays are applied annually in and around Manisa Province, which is the main area for viticulture in Turkey.

It is known that tank mixtures of chemicals are extensively used even though this is considered to be undesirable for vineyard production. When mixtures are made that are not recommended, phytotoxicity can occur or the intended desirable effects might not be obtained because the active ingredients and/or other substances react with each.

Pesticides are used separately in all registration experiments. Values such as maximum residue limits (MRL) and preharvest interval (PHI) are determined using data from these experiments. However, chemical can be applied in mixtures to save time and reduce depreciation of spray equipment. There are few studies of the problems caused by pesticides used in mixtures with fertilizers and adjuvants anywhere in the world, including changes in effects on pesticide residues. Ryckaert et al. (2007) measured effects of tolyfluanid mixed with four different adjuvants in lettuce and propiconazole mixed with six different adjuvants in wheat on pesticide degradation using chromatographic methods to determine effects of adjuvants on fungicides residues in leaves. The results showed that the adjuvants used in mixtures with fungicides slowed the process of degradation. Kucharski (2007) studied the effect of three different adjuvants (mineral oil, plant oil and surfactant) on phenmedipham, desmedipham and ethofumesate finding that they increased residues of the active ingredients by 52 and $33 \%$ in soil and plant, respectively. Kucharski \& Sadowski (2009a) found that mixtures of phenmedipham with oil adjuvant applied to soil slowed degradation of the pesticide. Similarly, Kucharski et al. $(2011,2012)$ and Kucharski \& Sadowski (2009b) showed that applications of separate ethofumesate, lenacil, chloridazon and their mixtures with oil adjuvant and surfactant applied to soil extended the PHI. Swarcewicz \& Gregorczyk (2012) applied pendimethalin to soil then single, double and triple combinations of metribuzin, mancozeb and thiamethoxam. Compared to application of pendimethalin alone, the mixtures were found to extend the PHI. Swarcewicz et al. (2013) tested the application of linuron alone and mixtures with mancozeb and thiamethoxam in soil under laboratory conditions and found that the PHI for linuron was extended. Another study conducted in Turkey found that humic materials mixed with pesticides impacted on the degradation process. Yılmaz \& Durmuşoğlu (2012) applied separate mixtures of imidacloprid to tomato leaves with humic acid and fulvic acid, and found that degradation of imidacloprid was accelerated and found the the same effect in the soil with humic acid, but with fulvic acid degradation was slower.

None of these studies examined degradation of pesticides mixed with plant growth regulators (PGR), foliar fertilizers (FF) and spreader-sticker (SS), as currently practiced. Viticulture is important globally and in Turkey, both for domestic consumption and export, however, these different additives have not been fully tested with the numerous pesticides used either in Turkey or elsewhere. Therefore, the main aim of this study was to determine whether degradation of pesticides mixed with PGR, FF and SS was changed. 


\section{Material and Methods}

A range of experiments were performed under laboratory and field conditions to determine changes in the process of degradation of pesticides in samples from spray tanks, and of grapevine leaves and fruit where PGR, FF and SS had been mixed with pesticides alone or various combinations. The study was undertaken during two grapevine development periods, shooting and fruiting, when pesticide residue problems particularly emerge. The shooting period is of concern because foliage is harvested for making a popular dish (sarma) in which meat or rice are wrapped in grapevine leaves. During both periods, pesticides and adjuvants of choice are used for controlling many significant pests and diseases, especially in Izmir and Manisa which are major production areas in Turkey. The details of the pesticides and adjuvants used in the experiments are presented in Tables 1 to 3.

Table 1. Pesticides used for the shooting period

\begin{tabular}{lllcr}
\hline Commercial name & Active ingredient and rate & Target organism & Application dose (g or ml/100 I water) & PHI (d) \\
\hline QuadrisMaxx SC & Azoxystrobin 250 g/l & Powdery mildew & 75 & 21 \\
Confidor SC & Imidacloprid 350 g/l & Thrips & 50 & 14 \\
Ridomil Gold MZ WG & Metalaxyl 4\% & Downy mildew & 250 & 14 \\
\hline
\end{tabular}

Table 2. Pesticides used for the fruiting period

\begin{tabular}{lllll}
\hline Commercial name & Active ingredient and rate & Target organism & Application dose (g or ml/100 I water) & PHI (d) \\
\hline Cantus WG & Boscalid 50\% & Gray mold & 120 & 7 \\
Dursban 4 EC & Chlorpyrifos-ethyl 480g/l & Grapevine moth & 100 & 14 \\
Nissorun 5 EC & Hexythiazox 50 g/l & Spider mite & 50 & 7 \\
\hline
\end{tabular}

Table 3. Adjuvants used for the shooting and fruiting periods

\begin{tabular}{|c|c|c|c|}
\hline Commercial name & Content and rate & Purpose & Application dose ( $\mathrm{g}$ or $\mathrm{ml} / 100$ I water) \\
\hline Vulcana Gold & Gibberellic acid $20 \mathrm{~g} / \mathrm{l}$ & Plant Growth Regulators & 120 \\
\hline Carnival - calcium nitrate & $\begin{array}{l}9 \% \text { nitrate nitrogen, } \\
15 \% \text { water-soluble calcium oxide, } \\
0.05 \% \text { water-soluble boron, } \\
0.02 \% \text { water-soluble zinc }\end{array}$ & Foliar Fertilizers & 150 \\
\hline Slygard 309 - organic silicon & $\begin{array}{l}80 \% \text { 3-(3-hydroxypropyl)- hepta- } \\
\text { methyltrisiloxane, ethoxlated, acetate }\end{array}$ & Spreader-Sticker & 30 \\
\hline
\end{tabular}

\section{Laboratory studies}

Physical and chromatographic analyses were performed in laboratory to establish whether the rate of degradation of pesticides in mixtures with PGR, FF and SS changed in spray tanks or on the grapevine. Physical and chromatographic analyses were performed at the Izmir Food Control Laboratory and Izmir Radix Analysis Laboratory (both accredited for pesticide residue analysis), respectively. 


\section{Physical analyses}

Physical analyses of pesticides and their mixtures with PGR, FF and SS were conducted using the criteria of pesticide formulations by FAO, WHO, EPA and CIPAC (WHO, 1984; FAO, 1985; EPA, 1996; CIPAC, 2006). The criteria evaluated included reactions in the solution (sudden cooling or warming, unexpected odor release or permanent foaming), changes in appearance (precipitation, agglomeration, sedimentation, decomposition or unexpected turbidity) and changes in $\mathrm{pH}$.

Liquid formulations were pipetted and solid formulations were weighed. These were placed in a 1-L beaker half filled with water and mixed with a magnetic stirrer. If a pesticide was analyzed alone, hard water is carefully added to the beaker to a final volume of $1 \mathrm{~L}$. If a pesticide was analyzed in a mixture, all ingredients were added to the beaker before the water and then mixed with a magnetic stirrer before dilution to the final volume.

\section{Physical analyses of mixtures of pesticides}

All pesticides were prepared according to the combinations shown in Table 4, such that the doses were twice the recommended dose.

Table 4. Doses prepared for physical analyses of mixtures of pesticides

\begin{tabular}{|c|c|c|c|}
\hline $\begin{array}{l}\text { Commercial names and active } \\
\text { ingredients of pesticides used for the } \\
\text { shooting period }\end{array}$ & $\begin{array}{l}\text { Used dose of pesticides } \\
\text { (g or } \mathrm{ml} / \mathrm{l} \text { water })\end{array}$ & $\begin{array}{c}\text { Commercial names and active } \\
\text { ingredients of pesticides used for } \\
\text { the fruiting period }\end{array}$ & $\begin{array}{l}\text { Used dose of pesticides } \\
\text { (g or } \mathrm{ml} / / \mathrm{l} \text { water) }\end{array}$ \\
\hline QuadrisMaxx - Azoxystrobin (A) & 1.5 & Cantus - Boscalid (B) & 2.4 \\
\hline Confidor - Imidacloprid (I) & 1.0 & Dursban - Chlorpyrifos-ethyl (C) & 2.0 \\
\hline Ridomil Gold - Metalaxyl (M) & 5.0 & Nissorun - Hexythiazox $(\mathrm{H})$ & 1.0 \\
\hline$A+1$ & $1.5+1.0$ & $B+C$ & $2.4+2.0$ \\
\hline$A+M$ & $1.5+5.0$ & $\mathrm{~B}+\mathrm{H}$ & $2.4+1.0$ \\
\hline$I+M$ & $1.0+5.0$ & $\mathrm{C}+\mathrm{H}$ & $2.0+1.0$ \\
\hline$A+I+M$ & $1.5+1.0+5.0$ & $\mathrm{~B}+\mathrm{C}+\mathrm{H}$ & $2.4+2.0+1.0$ \\
\hline
\end{tabular}

An experiment with three replicates and 14 treatments (two mixtures in seven combination) was conducted to determine if mixtures of pesticides lead to degradation in a spray tank. Mixtures were kept at room temperature for $10 \mathrm{~min}$, before preparation and assessment under the Regulations of Plant Protection Products by Ministry of Food Agriculture and Livestock, according to criteria given above.

\section{Physical analyses of mixtures of pesticides and adjuvants}

The mixture of pesticides including azoxystrobin, metalaxyl and imidacloprid is named Mixture 1, which was to represent combinations used during the shooting period when leaves can be harvested. The mixture was prepared using hard water. The mixture of pesticides including boscalid, chlorpyrifos ethyl and hexythiazox were called the Mixture 2, which was to represent combinations used during the fruiting periods when grapes are harvested, and was also prepared with hard water. Table 5 details the combination of these two mixtures with adjuvants. 
Table 5. Doses prepared for physical analyses of mixtures of pesticides with adjuvants

\begin{tabular}{lccc}
\hline $\begin{array}{c}\text { Mixtures of pesticides with } \\
\text { adjuvants used for the shooting } \\
\text { period* }\end{array}$ & $\begin{array}{c}\text { Used dose of adjuvants } \\
\text { (g or ml/l water) }\end{array}$ & $\begin{array}{c}\text { Mixtures of pesticides with } \\
\text { adjuvants used for the fruiting } \\
\text { period }\end{array}$ & $\begin{array}{c}\text { Used dose of adjuvants } \\
\text { (g or ml// water) }\end{array}$ \\
\hline $\begin{array}{l}\text { Mixture 1 + PGR } \\
\text { Mixture 1 + FF }\end{array}$ & 2.4 & Mixture 2 + PGR & 2.4 \\
Mixture 1 + SS & 0.6 & Mixture 2 + FF & 3.0 \\
Mixture 1 + PGR + FF & $2.4+3.0$ & Mixture 2 + SS & 0.6 \\
Mixture 1 + PGR + SS & $2.4+0.6$ & Mixture 2 + PGR + FF & $2.4+3.0$ \\
Mixture 1 + FF + SS & $3.0+0.6$ & Mixture 2 + PGR + SS & $2.4+0.6$ \\
Mixture 1 + PGR + FF + SS & $2.4+3.0+0.6$ & Mixture 2 + FF + SS & $3.0+0.6$ \\
\hline
\end{tabular}

* PGR, plant growth regulators; FF, foliar fertilizers; SS, spreader-sticker.

The combinations including PGR, FF and SS in single, double and triple combinations in three pesticides, which made it possible to reduce number of samples and analytical costs by avoiding unnecessary tests.

The second experiment was conducted with three replicates of these 14 treatments (Table 5) to determine if mixture of pesticides with PGR, FF and SS caused degradation in a spray tank. Assessments were the same as in the first experiment.

\section{Chromatographic analyses}

Chromatographic analyses were performed with Agilent 6460 Triple Quad LC-MS/MS (Liquid chromatography-tandem mass spectrometry) equipment. Calibration and recovery studies were conducted to determine recovery performance of calibration and extraction methods of the equipment used to perform residue analyses before assessing experimental samples. According to SANTE/11945/2015 document, at least three different levels are required for calibration. So, calibration was done with six concentrations $(5,10,25,50,100$ and $200 \mu \mathrm{g} / \mathrm{kg})$ considering the measurement range for each active ingredient used in the field. In the analyses, matrix matched calibration was used to compensate the matrix effect. Untreated leaf samples were collected from the vineyard and recovery studies conducted at three concentrations $(10,50$ and $200 \mu \mathrm{g} / \mathrm{kg})$ for each active ingredient. Details of the operating conditions of LC-MS/MS equipment used in chromatographic analyses are presented in Table 6.

Table 6. Operating parameters used for chromatographic analyses with the Agilent 6460 Triple Quard LC-MS/MS

\begin{tabular}{ll}
\hline Equipment Model & Agilent 6460 LC-MS/MS \\
\hline Detector & Triple Quard MS \\
Column & ${\text { Poroshell } C_{18}, 2.7 \mu \mathrm{m}, 3.0 \times 75 \mathrm{~mm}}_{\text {Mobile Phase A }}$ Ultra-pure water with $5 \mathrm{mM}$ ammonium formatted \\
Mobile Phase B & $100 \%$ acetonitrile \\
Flow Rate & $0.6 \mathrm{ml} / \mathrm{min}$ \\
Injection Volume & $5 \mu \mathrm{l}$ \\
Run Time & $12 \mathrm{~min}$ \\
\hline
\end{tabular}


Determination of the changes in the process of degradation of some pesticides applied in mixtures with plant growth regulators, foliar fertilizers and spreader-stricker in a vineyard

\section{Chromatographic analyses of mixtures of pesticides and adjuvants}

Pesticide and adjuvant mixtures (Table 5) for chromatographic analyses were prepared again as for the physical analyses.

Aliquots of $50 \mu \mathrm{l}$ were taken from each mixture and transferred to Teflon tubes with $50 \mathrm{ml}$ of ultrapure water to give a concentration of $0.1 \%$ to avoid any damage to the chromatographic equipment. These solutions were filtered through PTFE-Polytetrafluoro ethylene-0.20 $\mu$ l to remove particulate matter. Three replicates of each solution were analyzed with the LC-MS/MS system. Samples were taken and analyzed at three different times (10,60 and $120 \mathrm{~min}$ ) after preparation to simulate a situation in which pesticide mixtures are prepared in spray tank and used within $2 \mathrm{~h}$. Therefore, the experiment of 28 treatments (Tables 4 and 5 ) was analyzed in triplicate and at three times.

\section{Field experiments}

Field experiments were conducted in a vineyard located in Kemalpaşa County, Izmir Province. Two experiments were conducted, one during the shooting period (3 May 2016) and the other during the fruiting period (20 July 2016). The experiments were conducted using standard methods (Anonymous, 2011) for residue trials for plant protection products in plant products issued by Ministry of Food, Agriculture and Livestock. They were performed using back pulverizes in doses recommended for all pesticides and adjuvants. Experiments had a complete block trial design with in three replicates plots of four vines each.

\section{Assessment of degradation of pesticide residues on leave}

Degradation of the pesticides on grapevine leaves was determined following their application of Mixture 1 alone and in single, double and triple combinations with the adjuvants. Pesticide mixtures were applied soon after unsprayed control samples had been taken to determine if there had been any previous pesticide application. The sampling procedure was made considering days since the last standardized spraying and collect following the relevant ministry standards for such sampling. Leaf samples were taken for residue analyses at nine times; immediately before treatment, and $2 \mathrm{~h}$ and 1, 3, 5, 7, 10, 14 and $21 \mathrm{~d}$ after treatment. All samples were taken to laboratory in cold chain and stored in a deep freezer at $-80^{\circ} \mathrm{C}$ until analysis. The buffered solution of QuEChERS (Quick, Easy, Cheap, Effective, Rugged and Safe) method was used for the extraction (Lehotay et al., 2005; Lehotay, 2007).

The QuEChERS method uses a single-step buffered acetonitrile (MeCN) extraction and salting out liquid-liquid partitioning of the water in the sample with MgSO4. Dispersive-solid-phase extraction (dispersive-SPE) cleanup was done to remove organic acids, excess water, and other components with a combination of primary secondary amine (PSA) sorbent and MgSO4; then the extracts are analyzed by mass spectrometry (MS) after a chromatographic analytical separation (Lehotay, 2007). The basic steps of the QuEChERS method used were as follows. The sample was homogenized by blender, then $15 \mathrm{~g}$ transferred to a 50-ml teflon tube and shaken vigorously for $1 \mathrm{~min}$. Then $1.5 \mathrm{~g}$ of sodium acetate $+6 \mathrm{~g}$ magnesium sulfate was added and vortexed for $1 \mathrm{~min}$. After centrifuging for $4 \mathrm{~min}$ at $5000 \mathrm{rpm}$, an aliquot of $8 \mathrm{ml}$ of the acetonitrile phase was transferred to a 15-ml dispersive SPE tube containing $0.2 \mathrm{~g}$ PSA (primary secondary amine) and $0.6 \mathrm{~g} \mathrm{MgSO} 4$, and vortexed again for $1 \mathrm{~min}$, before centrifuging for $4 \mathrm{~min}$ at $5000 \mathrm{rpm}$. The upper phase was filtered and transferred to a vial for LC-MS/MS analysis.

Analysis of variance was used to statistically examine treatment effects. If significant differences $(P<0.05)$ were found, multiple comparison tests were applied to compare the means and LSMeans Student's t-test used for groupings. Data was analyzed with JMP 7.0 statistical program (JMP, 2007). 


\section{Assessment of degradation of pesticide residues on fruit}

Degradation of the pesticide residues on grapes was determined after application of Mixture 2 alone and in single, double and triple combinations with the adjuvants using the methods described above for the leaf samples.

\section{Results and Discussion}

\section{Physical analyses of mixtures of pesticides}

Table 7 gives the $\mathrm{pH}$ of solutions prepared with Mixtures 1 and 2. There were no significant changes in $\mathrm{pH}$ values and no other reactions were observed.

Table 7. $\mathrm{pH}$ of pesticide mixtures

\begin{tabular}{lclc}
\hline Treatment (shooting period) & $\mathrm{pH}($ mean $\pm \mathrm{SD})$ & Treatment (fruiting period) & $\mathrm{pH}($ mean $\pm \mathrm{SD})$ \\
\hline Azoxystrobin (A) & $7.64 \pm 0.01$ & Boscalid (B) & $7.48 \pm 0.10$ \\
Imidacloprid (I) & $7.09 \pm 0.03$ & Chlorpyrifos-ethyl (C) & $7.97 \pm 0.41$ \\
Metalaxyl (M) & $7.59 \pm 0.02$ & Hexythiazox $(\mathrm{H})$ & $7.45 \pm 0.11$ \\
$\mathrm{~A}+\mathrm{I}$ & $7.21 \pm 0.02$ & $\mathrm{~B}+\mathrm{C}$ & $7.93 \pm 0.05$ \\
$\mathrm{~A}+\mathrm{M}$ & $7.24 \pm 0.07$ & $\mathrm{~B}+\mathrm{H}$ & $7.22 \pm 0.04$ \\
$\mathrm{I}+\mathrm{M}$ & $7.11 \pm 0.04$ & $\mathrm{C}+\mathrm{H}$ & $7.84 \pm 0.04$ \\
$\mathrm{~A}+\mathrm{I}+\mathrm{M}$ & $7.12 \pm 0.03$ & $\mathrm{~B}+\mathrm{C}+\mathrm{H}$ & $7.83 \pm 0.05$ \\
\hline
\end{tabular}

\section{Physical analyses of mixtures of pesticides and adjuvants}

Table 8 gives the $\mathrm{pH}$ of solutions prepared with Mixtures 1 and 2 and adjuvants. There were no significant changes in $\mathrm{pH}$ values and no other reactions were observed. The $\mathrm{pH}$ of the PGR, FF and SS alone were $7.25,6.72$ and 7.59 , respectively.

Table 8. $\mathrm{pH}$ of pesticide and adjuvant mixtures

\begin{tabular}{lclc}
\hline Treatment $^{*}$ (shooting period) & $\mathrm{pH}($ mean \pm SD) & Treatment (fruiting period) & $\mathrm{pH}($ mean \pm SD) \\
\hline Mixture 1 + FF & $7.04 \pm 0.06$ & Mixture 2 + FF & $7.27 \pm 0.05$ \\
Mixture 1 + SS & $7.43 \pm 0.05$ & Mixture 2 + SS & $7.62 \pm 0.04$ \\
Mixture 1 + PGR & $7.19 \pm 0.05$ & Mixture 2 + PGR & $7.43 \pm 0.06$ \\
Mixture 1 + FF + SS & $7.03 \pm 0.05$ & Mixture 2 + FF + SS & $7.55 \pm 0.20$ \\
Mixture 1 + FF + PGR & $6.99 \pm 0.07$ & Mixture 2 + FF + PGR & $7.49 \pm 0.07$ \\
Mixture 1 + SS + PGR & $7.19 \pm 0.06$ & Mixture 2 + SS + PGR & $7.34 \pm 0.02$ \\
Mixture 1 + FF + SS + PGR & $7.13 \pm 0.05$ & Mixture 2 + FF + SS + PGR & $7.53 \pm 0.06$ \\
\hline
\end{tabular}

* PGR, plant growth regulators; FF, foliar fertilizers; SS, spreader-sticker.

\section{Chromatographic analyses}

\section{Calibration and recovery}

Correlation coefficients calculated for the calibration curves were 0.996 for azoxystrobin, 0.995 for metalaxyl, 0.992 for imidacloprid, 0.990 for boscalid, 0.997 for chlorpyrifos ethyl, 0.993 for hexythiazox. Miller \& Ambrus (2005) reported that the coefficients for acceptance of linear calibration should be $\geq 0.99$. 
Determination of the changes in the process of degradation of some pesticides applied in mixtures with plant growth regulators, foliar fertilizers and spreader-stricker in a vineyard

Triplicate recovery studies conducted for three different concentrations $(0.01,0.05$ and $0.20 \mathrm{mg} / \mathrm{kg})$ of each active ingredient gave average recovery of $0.0105,0.0524,0.2098 \mathrm{mg} / \mathrm{kg}$ for azoxystrobin; 0.079 , $0.0546,0.1991 \mathrm{mg} / \mathrm{kg}$ for imidacloprid; $0.0804,0.0530,0.1992 \mathrm{mg} / \mathrm{kg}$ for metalaxyl; $0.0924,0.0576$, $0.1983 \mathrm{mg} / \mathrm{kg}$ for boscalid; $11.24,48.24,200.31 \mathrm{mg} / \mathrm{kg}$ for chlorpyrifos; and 0.0106, $0.04920 .2002 \mathrm{mg} / \mathrm{kg}$ for hexythiazox, respectively. According to SANTE (2015) 'Method Validation and Quality Control Procedures for Pesticide Residue Analysis in Foods and Feeds', recovery values must be within the range of $70-120 \%$, which was achieved in the current study.

\section{Mixtures of pesticides and adjuvants in a spray tank}

Tables 9 to 12 summarizes the results the degradation of pesticides in mixtures with and without adjuvants in a spray tank. Given the dilutions used in the analysis, the expect concentrations for Mixture 1 were $0.5,11.5$ and $1.5 \mathrm{mg} / \mathrm{kg}$ for azoxystrobin, imidacloprid and metalaxyl, respectively. In Mixture 2 to the expected concentrations were $11.5,10$ and $2 \mathrm{mg} / \mathrm{kg}$ for boscalid, chlorpyrifos ethyl and hexythiazox, respectively.

It is clear from Tables 9 to 12 that values quite very close to the expected values when measured 2-h period after pesticides mixtures were prepared. The variation between the values is consistent with normal experimental error, and variation in laboratory measurement variation and the of sensitivity in equipment. Therefore, mixtures of pesticides did not cause and statistically significant changes in in the first $2 \mathrm{~h}$, which is the normally recommended maximum time between mixing and application of pesticides.

Considering various factors, such as $\mathrm{pH}$ and hardness and mineral content of water in spray tank as well as chemical properties of pesticides, numerous studies (Okdemir et al., 1965; Ağar et al., 1991; Fishel, 2002; Whitford, 2009; Lo \& Lee, 2010; Park \& Chong, 2010) have examined the effects of such factors on degradation of pesticides. For example, one study examining the effects of humic matter mixed with pesticides (Yılmaz \& Durmuşoğlu, 2012) showed no significant effects of humic matter on acetamiprid, imidacloprid and pymetrozine.

Table 9. Residues $(\mathrm{mg} / \mathrm{kg}$ ) in pesticides mixtures (Mixture 1) at different sampling times

\begin{tabular}{llccc}
\hline \multirow{2}{*}{ Active Ingredient } & Treatment & \multicolumn{3}{c}{ Sampling times } \\
\cline { 3 - 4 } & & $10 \mathrm{~min}$ & $60 \mathrm{~min}$ & $\begin{array}{c}120 \mathrm{~min} \\
\text { Mean } \pm \text { SD }\end{array}$ \\
\hline \multirow{3}{*}{ Azoxystrobin } & Azoxystrobin & $0.48 \pm 0.01$ & $0.48 \pm 0.00$ & $0.47 \pm 0.01$ \\
& Azoxystrobin + Metalaxyl & $0.46 \pm 0.00$ & $0.48 \pm 0.01$ & $0.45 \pm 0.02$ \\
& Azoxystrobin + Imidacloprid & $0.47 \pm 0.00$ & $0.46 \pm 0.00$ & $0.46 \pm 0.00$ \\
& Azoxystrobin + Metalaxyl + Imidacloprid & $0.49 \pm 0.01$ & $0.48 \pm 0.01$ & $0.48 \pm 0.01$ \\
\hline \multirow{3}{*}{ Imidacloprid } & Imidacloprid & $11.57 \pm 0.05$ & $11.15 \pm 0.08$ & $11.52 \pm 0.07$ \\
& Imidacloprid + Azoxystrobin & $11.02 \pm 0.15$ & $11.13 \pm 0.07$ & $11.40 \pm 0.08$ \\
& Imidacloprid + Metalaxyl & $11.11 \pm 0.09$ & $11.06 \pm 0.10$ & $11.22 \pm 0.32$ \\
& Imidacloprid + Azoxystrobin + Metalaxyl & $11.47 \pm 0.31$ & $11.70 \pm 0.15$ & $11.43 \pm 0.14$ \\
\hline \multirow{3}{*}{ Metalaxyl } & Metalaxyl & $1.40 \pm 0.01$ & $1.45 \pm 0.01$ & $1.45 \pm 0.01$ \\
& Metalaxyl + Azoxystrobin & $1.50 \pm 0.01$ & $1.46 \pm 0.00$ & $1.48 \pm 0.02$ \\
& Metalaxyl + Imidacloprid & $1.60 \pm 0.01$ & $1.60 \pm 0.01$ & $1.58 \pm 0.01$ \\
& Metalaxyl + Azoxystrobin + Imidacloprid & $1.54 \pm 0.00$ & $1.54 \pm 0.01$ & $1.52 \pm 0.02$ \\
\hline
\end{tabular}

According to the LSMeans Student's t-test $(P>0.05)$ there was no difference between the values in the groups. 
Table 10. Residues $(\mathrm{mg} / \mathrm{kg})$ in pesticides mixtures (Mixture 2) at different sampling times

\begin{tabular}{llrrc}
\hline \multirow{2}{*}{ Active Ingredient } & Treatment & \multicolumn{3}{c}{ Sampling times } \\
\cline { 2 - 5 } & Boscalid & $\begin{array}{c}60 \mathrm{~min} \\
\text { Mean } \pm \text { SD }\end{array}$ & $\begin{array}{c}120 \mathrm{~min} \\
\text { Mean } \pm \text { SD }\end{array}$ \\
\cline { 2 - 5 } Boscalid & Boscalid + Chlorpyrifos ethyl & $11.85 \pm 0.09$ & $11.60 \pm 0.07$ & $11.17 \pm 0.07$ \\
& Boscalid + Hexythiazox & $11.72 \pm 0.06$ & $11.42 \pm 0.10$ & $11.01 \pm 0.20$ \\
& Boscalid + Chlorpyrifos ethyl + Heyxthiazox & $11.39 \pm 0.43$ & $11.27 \pm 0.33$ & $10.81 \pm 0.75$ \\
& Chlorpyrifos ethyl & $10.82 \pm 1.20$ & $10.96 \pm 0.41$ & $11.52 \pm 0.41$ \\
\hline \multirow{3}{*}{ Chlorpyrifos-ethyl } & Chlorpyrifos ethyl + Boscalid & $9.79 \pm 0.42$ & $9.42 \pm 0.68$ & $10.05 \pm 0.73$ \\
& Chlorpyrifos ethyl + Hexythiazox & $10.17 \pm 0.03$ & $10.59 \pm 0.36$ & $11.11 \pm 0.17$ \\
& Chlorpyrifos ethyl + Boscalid + Hexythiazox & $10.28 \pm 0.38$ & $10.33 \pm 0.36$ & $9.88 \pm 0.41$ \\
\hline Hexythiazox & Hexythiazox & $2.27 \pm 0.10$ & $2.22 \pm 0.10$ & $2.36 \pm 0.12$ \\
& Hexythiazox + Boscalid & $2.05 \pm 0.10$ & $1.98 \pm 0.12$ & $2.10 \pm 0.18$ \\
& Hexythiazox + Chlorpyrifos ethyl & $1.93 \pm 0.23$ & $1.90 \pm 0.23$ & $2.02 \pm 0.16$ \\
& Hexythiazox + Boscalid + Chlorpyrifos ethyl & $2.15 \pm 0.15$ & $2.06 \pm 0.10$ & $2.08 \pm 0.23$ \\
\hline
\end{tabular}

According to the LSMeans Student's t-test $(P>0.05)$ there was no difference between the values in the groups.

Table 11. Residues (mg/kg) in pesticide (Mixture 1) and adjuvant mixtures at different sampling times

\begin{tabular}{|c|c|c|c|c|}
\hline \multirow[b]{2}{*}{ Active Ingredient } & \multirow[b]{2}{*}{ Treatment } & \multicolumn{3}{|c|}{ Sampling times } \\
\hline & & $\begin{array}{c}10 \min \\
(\text { mean } \pm S D)\end{array}$ & $\begin{array}{c}60 \mathrm{~min} \\
(\mathrm{mean} \pm \mathrm{SD})\end{array}$ & $\begin{array}{c}120 \min \\
(\text { mean } \pm S D)\end{array}$ \\
\hline \multirow{8}{*}{ Azoxystrobib } & Mixture $1(A+I+M)^{*}$ & $0.49 \pm 0.01$ & $0.48 \pm 0.01$ & $0.48 \pm 0.02$ \\
\hline & Mixture $1+F F$ & $0.54 \pm 0.01$ & $0.49 \pm 0.02$ & $0.50 \pm 0.02$ \\
\hline & Mixture $1+P G R$ & $0.51 \pm 0.01$ & $0.49 \pm 0.01$ & $0.51 \pm 0.01$ \\
\hline & Mixture $1+\mathrm{SS}$ & $0.49 \pm 0.02$ & $0.48 \pm 0.03$ & $0.51 \pm 0.02$ \\
\hline & Mixture $1+F F+P G R$ & $0.50 \pm 0.01$ & $0.50 \pm 0.04$ & $0.53 \pm 0.03$ \\
\hline & Mixture $1+F F+S S$ & $0.50 \pm 0.01$ & $0.55 \pm 0.04$ & $0.54 \pm 0.05$ \\
\hline & Mixture $1+P G R+S S$ & $0.52 \pm 0.02$ & $0.49 \pm 0.01$ & $0.49 \pm 0.03$ \\
\hline & Mixture $1+F F+P G R+S S$ & $0.51 \pm 0.02$ & $0.50 \pm 0.04$ & $0.51 \pm 0.03$ \\
\hline \multirow{8}{*}{ Imidacloprid } & Mixture $1(A+I+M)$ & $11.47 \pm 0.31$ & $11.70 \pm 0.15$ & $11.43 \pm 0.14$ \\
\hline & Mixture $1+F F$ & $11.60 \pm 0.31$ & $11.23 \pm 0.18$ & $11.25 \pm 0.52$ \\
\hline & Mixture $1+$ PGR & $11.49 \pm 0.42$ & $11.87 \pm 0.55$ & $11.57 \pm 0.30$ \\
\hline & Mixture $1+\mathrm{SS}$ & $11.74 \pm 0.34$ & $11.48 \pm 0.39$ & $11.22 \pm 0.20$ \\
\hline & Mixture $1+F F+P G R$ & $11.98 \pm 0.67$ & $11.80 \pm 0.59$ & $11.48 \pm 0.27$ \\
\hline & Mixture $1+F F+S S$ & $11.22 \pm 0.61$ & $11.59 \pm 0.38$ & $11.55 \pm 0.16$ \\
\hline & Mixture $1+P G R+S S$ & $11.80 \pm 0.98$ & $11.44 \pm 0.21$ & $11.67 \pm 0.54$ \\
\hline & Mixture $1+F F+P G R+S S$ & $11.82 \pm 1.11$ & $11.93 \pm 0.34$ & $11.92 \pm 0.21$ \\
\hline \multirow{8}{*}{ Metalaxyl } & Mixture $1(A+I+M)$ & $1.54 \pm 0.00$ & $1.54 \pm 0.01$ & $1.52 \pm 0.02$ \\
\hline & Mixture $1+F F$ & $1.63 \pm 0.03$ & $1.57 \pm 0.04$ & $1.55 \pm 0.07$ \\
\hline & Mixture $1+P G R$ & $1.55 \pm 0.06$ & $1.58 \pm 0.02$ & $1.54 \pm 0.08$ \\
\hline & Mixture $1+\mathrm{SS}$ & $1.55 \pm 0.08$ & $1.56 \pm 0.10$ & $1.53 \pm 0.05$ \\
\hline & Mixture $1+F F+P G R$ & $1.58 \pm 0.05$ & $1.49 \pm 0.07$ & $1.58 \pm 0.05$ \\
\hline & Mixture $1+F F+S S$ & $1.57 \pm 0.04$ & $1.65 \pm 0.10$ & $1.56 \pm 0.06$ \\
\hline & Mixture $1+P G R+S S$ & $1.58 \pm 0.05$ & $1.50 \pm 0.04$ & $1.53 \pm 0.04$ \\
\hline & Mixture $1+F F+P G R+S S$ & $1.61 \pm 0.05$ & $1.59 \pm 0.08$ & $1.63 \pm 0.10$ \\
\hline
\end{tabular}

${ }^{*} \mathrm{~A}+\mathrm{I}+\mathrm{M}$, Azoxystrobin + Imidacloprid + Metalaxyl; PGR, plant growth regulators; FF, foliar fertilizers; SS, spreader-sticker According to the LSMeans Student's t-test $(P>0.05)$ there was no difference between the values in the groups. 
Determination of the changes in the process of degradation of some pesticides applied in mixtures with plant growth regulators, foliar fertilizers and spreader-stricker in a vineyard

Table 12. Residues (mg/kg) in pesticide (Mixture 2) and adjuvant mixtures at different sampling times

\begin{tabular}{|c|c|c|c|c|}
\hline \multirow[b]{2}{*}{ Active Ingredient } & \multirow[b]{2}{*}{ Treatment } & \multicolumn{3}{|c|}{ Sampling times } \\
\hline & & $\begin{array}{c}10 \text { min } \\
(m e a n \pm S D)\end{array}$ & $\begin{array}{c}60 \mathrm{~min} \\
(\mathrm{mean} \pm \mathrm{SD})\end{array}$ & $\begin{array}{c}120 \min \\
(\text { mean } \pm S D)\end{array}$ \\
\hline \multirow{8}{*}{ Boscalid } & Mixture $2(B+C+H)^{*}$ & $10.82 \pm 1.20$ & $10.96 \pm 0.41$ & $11.52 \pm .041$ \\
\hline & Mixture $2+\mathrm{FF}$ & $11.34 \pm 0.37$ & $11.30 \pm 0.32$ & $10.22 \pm 0.58$ \\
\hline & Mixture 2 + PGR & $11.30 \pm 0.08$ & $11.25 \pm 0.35$ & $11.17 \pm 0.21$ \\
\hline & Mixture $2+S S$ & $11.76 \pm 0.74$ & $11.53 \pm 0.63$ & $11.86 \pm 0.55$ \\
\hline & Mixture $2+F F+P G R$ & $11.58 \pm 0.38$ & $11.33 \pm 0.34$ & $11.41 \pm 0.35$ \\
\hline & Mixture $2+F F+S S$ & $11.80 \pm 0.42$ & $11.55 \pm 0.44$ & $11.41 \pm 0.52$ \\
\hline & Mixture $2+P G R+S S$ & $11.86 \pm 0.09$ & $11.94 \pm 0.52$ & $11.71 \pm 0.54$ \\
\hline & Mixture $2+F F+P G R+S S$ & $11.44 \pm 0.25$ & $11.32 \pm 0.17$ & $11.41 \pm 0.12$ \\
\hline \multirow{8}{*}{ Chlorpyrifos ethyl } & Mixture $2(\mathrm{~B}+\mathrm{C}+\mathrm{H})$ & $10.28 \pm 0.38$ & $10.33 \pm 0.36$ & $9.88 \pm 0.41$ \\
\hline & Mixture $2+F F$ & $9.93 \pm 0.63$ & $9.87 \pm 0.32$ & $10.16 \pm 0.27$ \\
\hline & Mixture 2 + PGR & $9.97 \pm 0.64$ & $10.32 \pm 0.49$ & $9.85 \pm 0.20$ \\
\hline & Mixture $2+S S$ & $10.24 \pm 0.43$ & $10.10 \pm 0.20$ & $10.36 \pm 0.04$ \\
\hline & Mixture $2+F F+P G R$ & $9.57 \pm 0.59$ & $9.90 \pm 0.23$ & $10.11 \pm 0.18$ \\
\hline & Mixture $2+F F+S S$ & $10.06 \pm 0.73$ & $9.93 \pm 0.35$ & $9.77 \pm 0.44$ \\
\hline & Mixture $2+P G R+S S$ & $10.10 \pm 0.55$ & $9.66 \pm 0.88$ & $10.00 \pm 0.39$ \\
\hline & Mixture $2+F F+P G R+S S$ & $10.39 \pm 0.52$ & $9.98 \pm 0.51$ & $9.78 \pm 0.42$ \\
\hline \multirow{8}{*}{ Hexythiazox } & Mixture $2(B+C+H)$ & $2.15 \pm 0.15$ & $2.06 \pm 0.10$ & $2.08 \pm 0.23$ \\
\hline & Mixture $2+F F$ & $2.13 \pm 0.12$ & $2.03 \pm 0.06$ & $2.09 \pm 0.11$ \\
\hline & Mixture 2 + PGR & $1.84 \pm 0.04$ & $1.85 \pm 0.14$ & $1.89 \pm 0.11$ \\
\hline & Mixture $2+S S$ & $1.98 \pm 0.25$ & $1.94 \pm 0.07$ & $2.08 \pm 0.22$ \\
\hline & Mixture 2 + FF + PGR & $2.01 \pm 0.18$ & $2.04 \pm 0.12$ & $2.02 \pm 0.17$ \\
\hline & Mixture $2+F F+S S$ & $1.92 \pm 0.11$ & $2.16 \pm 0.17$ & $2.18 \pm 0.11$ \\
\hline & Mixture $2+P G R+S S$ & $1.85 \pm 0.11$ & $1.94 \pm 0.09$ & $1.90 \pm 0.04$ \\
\hline & Mixture $2+F F+P G R+S S$ & $2.09 \pm 0.20$ & $2.10 \pm 0.24$ & $1.96 \pm 0.02$ \\
\hline
\end{tabular}

${ }^{*} \mathrm{~B}+\mathrm{C}+\mathrm{H}$, Boscalid + Chlorpyrifos ethyl + Hexythiazox; PGR, plant growth regulators; FF, foliar fertilizers; SS, spreader-sticker According to the LSMeans Student's t-test $(P>0.05)$ there was no difference between the values in the groups.

\section{Pesticide residues on leaves}

No residues were found on the unsprayed control leaf samples collected immediately before treatment. Tables 13 to 15 summarizes the results of the degradation of active ingredients in mixtures containing azoxystrobin, imidacloprid and metalaxyl applied during the shooting period.

Table 13 shows the residues of azoxystrobin on leaves in different sampling times. The residues on leaves at the end of PHI (21 d) for azoxystrobin were over MRL in mixtures with PGR + SS, PGR + FF and $P G R+F F+S S$. 


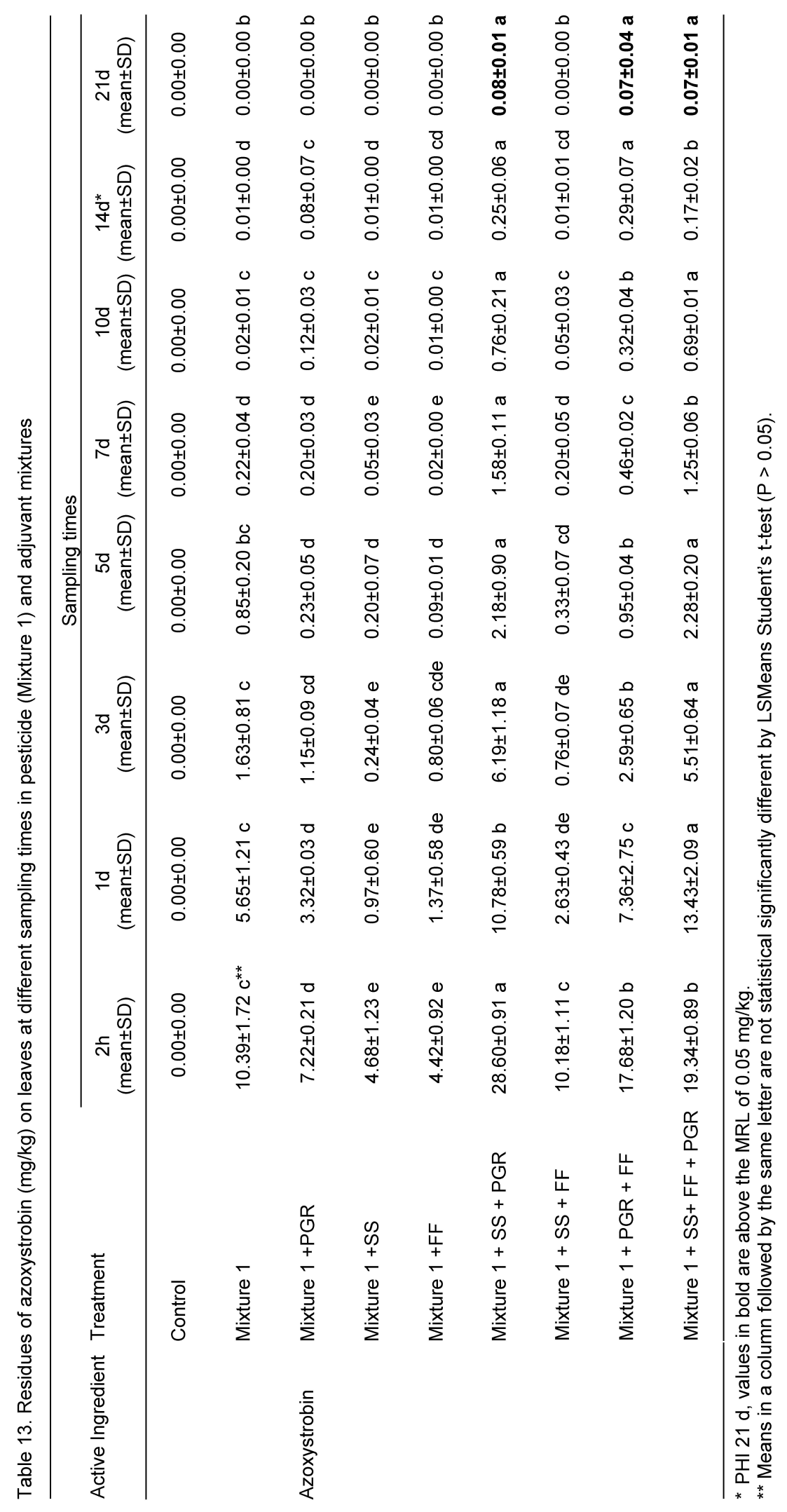




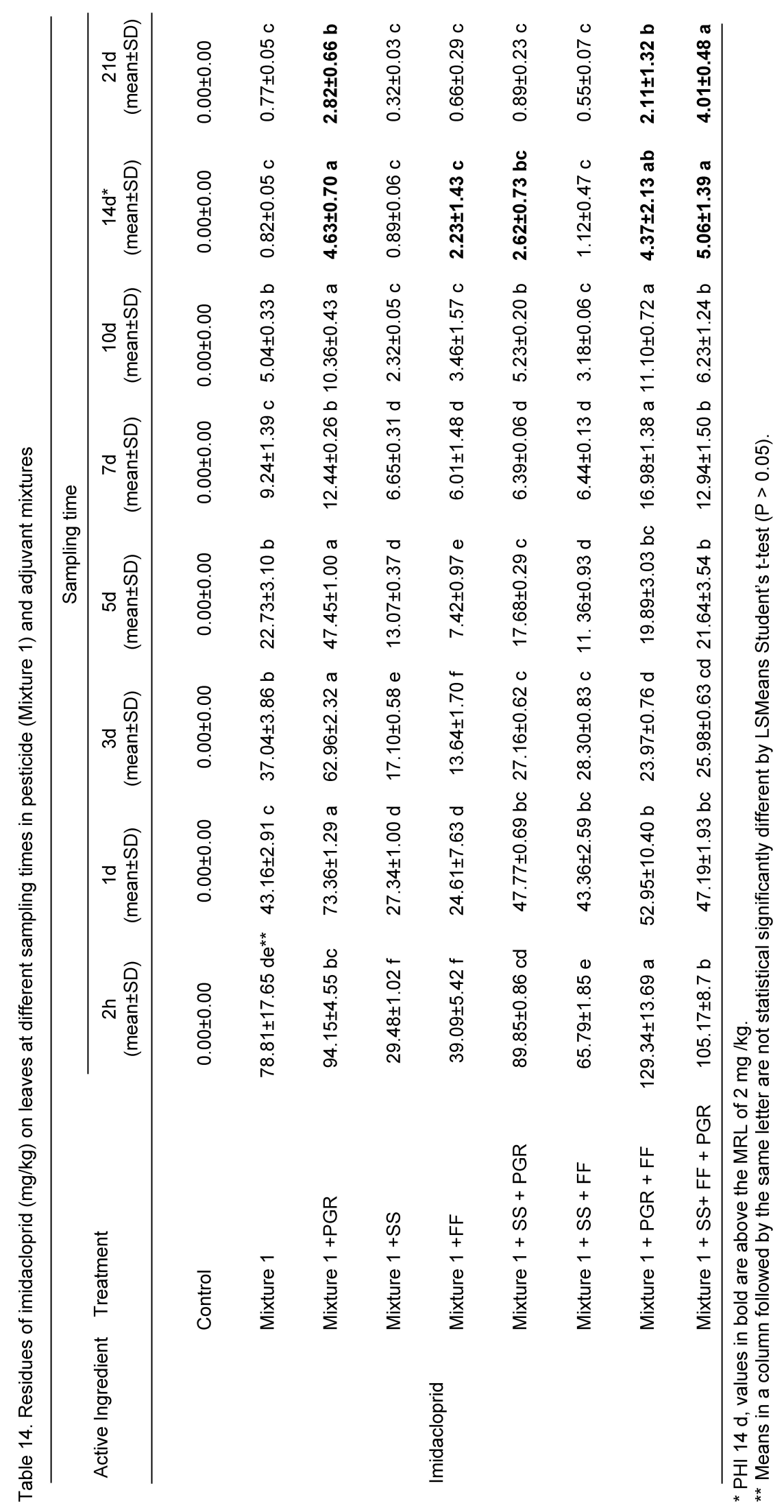




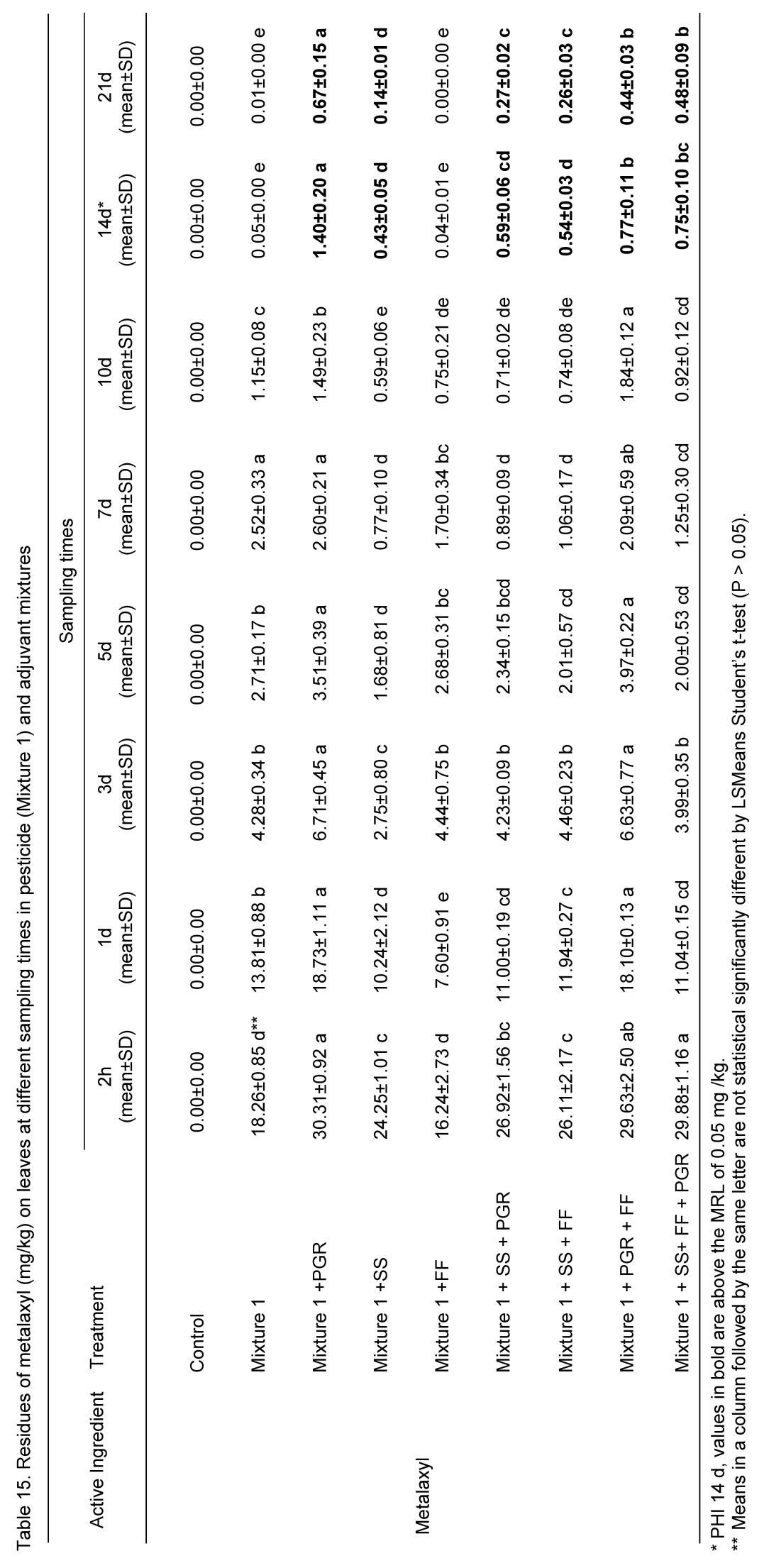


Determination of the changes in the process of degradation of some pesticides applied in mixtures with plant growth regulators, foliar fertilizers and spreader-stricker in a vineyard

Table 14 shows the residue of imidacloprid on leaf samples after $14 \mathrm{~d}$ dropped below the expected level following its application without adjuvants, but in mixtures with SS and with SS + FF the residues of remained above the MRL despite PHI (14 d). Therefore, regardless of PHI of $14 \mathrm{~d}$, mixtures were found with residues over the MRL even in the samples collected after $21 \mathrm{~d}$. For example, leaf samples from plots treated with a mixture including PGR had $2.82 \mathrm{mg} / \mathrm{kg}$ imidacloprid even after $21 \mathrm{~d}$. Also, when it was applied with PGR + FF, the same problem occurred and its residue approached the MRL at $2.11 \mathrm{mg} / \mathrm{kg}$. The treatment with the three adjuvants had a residue of $5.06 \mathrm{mg} / \mathrm{kg}$ in leaf samples collected after $14 \mathrm{~d}$, remaining much higher than MRL and even leaf samples following $21 \mathrm{~d}$ also exhibited a residue as much twice the MRL. Mixing with PGR + FF + SS slowed degradation of imidacloprid leading to the highest residue.

For metalaxyl only two treatments were below of MRL at 14 and $21 \mathrm{~d}$; i.e., metalaxyl with adjuvants and with FF (Table 15). All other treatments have residues above MRL even after $21 \mathrm{~d}$, so they had slowed the degradation of metalaxyl.

\section{Pesticide residues on fruit}

Residues of boscalid, chlorpyrifos ethyl and hexythiazox for treatments applied during the fruiting period are given in Tables 16 to 18. No residues were detected in the unsprayed controls collected just before the application of the treatments.

Degradation of boscalid (Table 16) on the grape samples when applied without adjuvants was faster than in mixtures with adjuvants, and after $7 \mathrm{~d}$ its residue was under the MRL. Wheres, with all combinations with adjuvants after $7 \mathrm{~d}$ residue exceeded the MRL. Chlorpyrifos ethyl residues at PHI of 14 $\mathrm{d}$ were below the MRL in all treatments (Table 17). However, considering the reports published by EPA and EFSA concerning plant protection products including chlorpyrifos ethyl emphasized its danger for human health and the directive of EU in August 2016 to set the MRL for chlorpyrifos ethyl to $0.01 \mathrm{mg} / \mathrm{kg}$, the residues in all the samples after $14 \mathrm{~d}$ were above this EU MRL. The resides of hexythiazox, were below the MRL in all treatments after $7 \mathrm{~d}$, in other words at the end of PHI (Table 18).

Although there are no similar studies published for grapevines or other contexts, there are some studies on effects of a number of adjuvants on the degradation of pesticides. Kucharski (2007) reported that three different adjuvants (mineral oil, plant oil and surfactant) applied to sugar beet and soil increased the residues of phenmedipham, desmedipham and ethofumesate. Consistent with the findings reported hare, Kucharski \& Sadowski (2009b) reported that mixture of an oil adjuvant with ethofumesate tended to decrease degradation of ethofumesate applied alone ( $\mathrm{PHI}$ increased at 8 to10 d) and the residue in soil was higher. Kucharski et al. $(2011 ; 2012)$ repeated the same study using lenacil and chloridazon with similar results. Another study supportive of the present one was reported by Ryckaert et al. (2007). It was reported that some adjuvants mixed with tolyfluanid increased residues compared to controls in pepper, but mixture of tolyfluanid with another adjuvant, magic sticker, showed the opposite effect. The sticker increased the rate of degradation of tolyfluanid and thus decreased its residue. From the present study, it follows that mixture of FF with pesticides reduces residues of some active ingredients but decelerated the degradation of others with a risk that the residues could exceed the MRL. In fact, another study similar to the present one conducted by Yılmaz \& Durmuşoğlu (2012) showed that combination of humic matter with imidacloprid applied on leaves, (humic and fulvic acid) accelerated up the degradation of that active ingredient. However, application of imidacloprid with fulvic acid to soil was observed to accelerate uptake of imidacloprid by the plant, as well as decelerate and lengthen the process of degradation. Application of imidacloprid with humic acid to soil was found to retard transport of imidacloprid to leaves, as well as speed up the process of degradation. Consequently, application of pesticides with humic matter was reported to be likely to cause changes in the process of degradation residues in plants, which could cause variable results depending the humic matter content and chemical properties of the pesticides.

It is clear from the results for grapevine leaves that most mixtures gave residues above MRL $s$ for most of active ingredients, with a few exceptions. The MRL for grapevine leaves are the lowest, based on

LOD (limit of detection), under Turkish Food Codex which adopts the EU analytically lowest limit. 


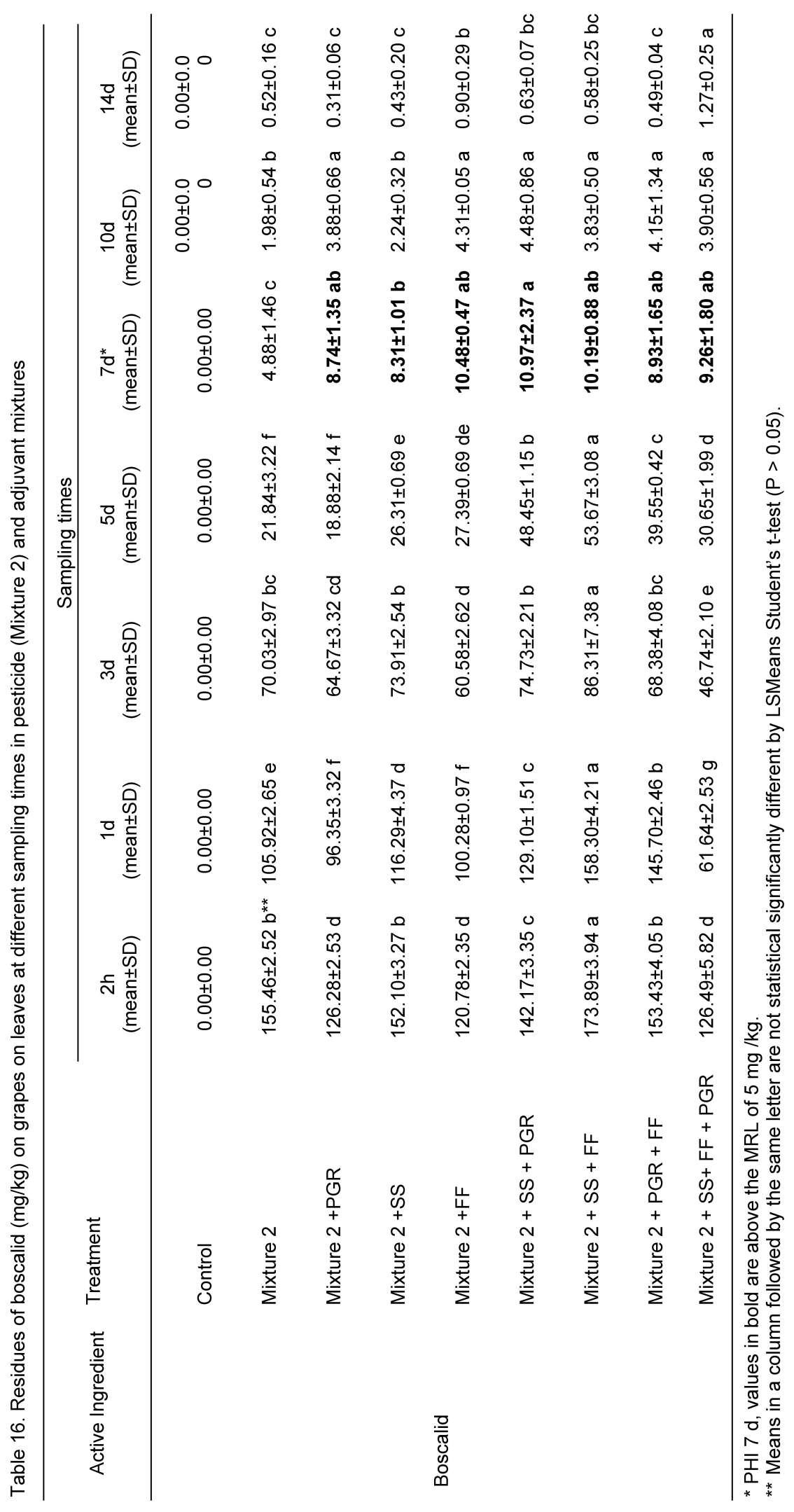




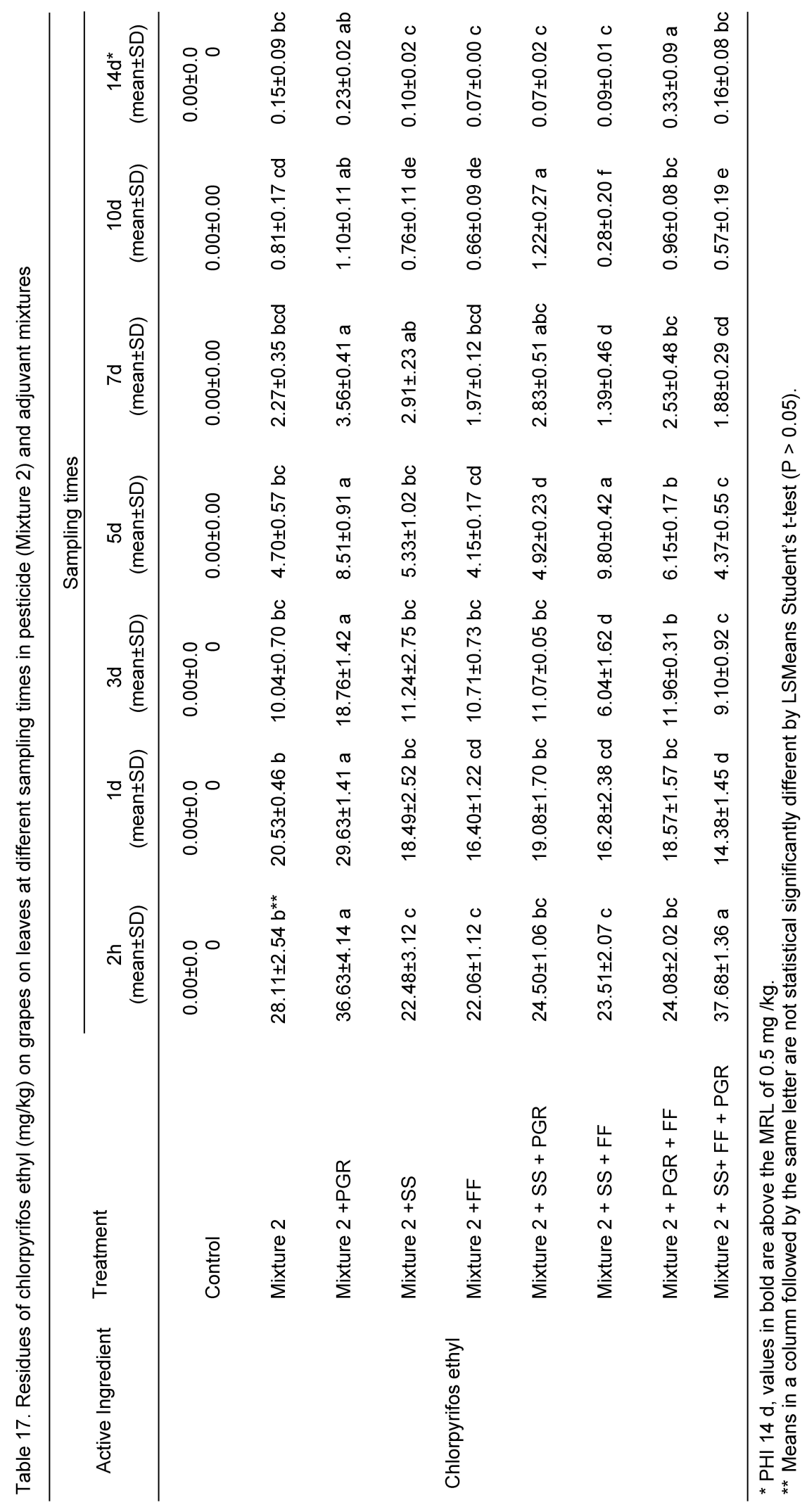







Determination of the changes in the process of degradation of some pesticides applied in mixtures with plant growth regulators, foliar fertilizers and spreader-stricker in a vineyard

Considering the results from the fruiting period with application of a mixture of boscalid, chlorpyrifos ethyl and hexythiazox (Mixture 2), single, double and triple mixtures with PGR, FF and SS tended to lengthen the process of degradation of boscalid but did not affect the degradation of chlorpyrifos ethyl and hexythiazox. In summary, PGR, FF and SS affected the process of degradation of some active ingredients with some failing to drop below the MRL even after the PHI.

Despite the fact that producers comply with the $\mathrm{PHI}$ on the pesticide labels, the unexpected residue problem caused by the additives in mixtures could negatively affects the health of consumers. The practical benefits of mixtures in conjunction with the lack of information on the effects of these mixtures motivated for this work, which attempted address some unanswered questions on this topic. Nevertheless, the pesticides used in this study should be further investigated by examining the effects of other preparations using PGR, FF and SS in different concentrations. Likewise, other active ingredients and mixtures, and other cultivated plants need to be studied. It is also recommended that manufacturers be informed about tank mixes and their potential risks. Similarly, it should be emphasized that, while pesticides approved for cultivated plants are recommended to producers, producers should not mix with unapproved adjuvants.

In conclusion, it was observed that using pesticides in mixtures with PGR, FF and SS could lead to slower degradation and higher residues, and this could vary with chemical properties of the pesticide, and nature and concentration of the adjuvants.

\section{Acknowledgments}

We thank the Izmir Food Control Laboratory Directorate and Private Radix Analysis Laboratories for their analyses.

\section{References}

Ağar, S., M. Durgun, B. Evyapan \& S. Öztürk, 1991. Investigations on the character of the waters, for preparing pesticide mixture, in the regions that plant protection chemicals are used intensively in Turkey. Plant Protection Bulletin, 31 (1-4): 99-108.

Anonymous, 2011. T.C. General Directorate of Agricultural Research and Policies. Standard testing methods for the preparation of storage terminals of plant protection products in plant or vegetable products. (Web page: https://www.tarim.gov.tr/TAGEM/Belgeler/yayin/22.pdf) (Date accessed: June 2015).

Anonymous, 2014. Federation of Food \& Drink Industry Associations of Turkey (Web page: http://www.tgdf.org.tr/ turkce/tgdfraporlari/11uzum.pdf) (Date accessed: November 2014).

CIPAC, 2006. Collaborative International Pesticide Analytical Council, Content Handbook. 45 pp.

Copçu, M., N. Öngen, V. Çetin \& K. Atalay, 2002. Correct deployment in the vinification program and pesticide burden reduction studies. Turkey V. Viticulture and Oenology Symposium. Nevşehir, 572 pp.

Durmuşoğlu, E., O. Tiryaki \& R. Canhilal, 2010. Pesticide use in Turkey, residual and resistance problems. (Web page: http://www.zmo.org.tr/resimler/ekler/52cf38361a20908_ek.pdf) (Date accessed: May 2016).

EPA, 1996. United States Environmental Protection Agency, Product Properties Test Guidelines, OPPTS 830.6317.

FAO, 1985. Food and Agriculture Organization of The United Nations, Guidelines for the Packaging and Storage of Pesticides. (Web page: http://www.fao.org/home/en/) (Date accessed: November 2014).

Fishel, F., 2002. Effects of water pH on the stability of pesticides. (Web page: https://extension2.missouri.edu/ ipm1017) (Date accessed: May 2016).

JMP, 2007. Version 7.0. SAS Institute Inc., Cary, NC.

Kucharski, M., 2007. Impact of adjuvants on: Phenmedipham, desmedipham and ethofumesate residues in soil and plant. Pestycydy, (3-4): 53-59.

Kucharski, M. \& J. Sadowski, 2009a. Influence of adjuvants on behavior of phenmedipham in plant and soil. Polish Journal of Agronomy, 1: 32-36. 
Kucharski, M. \& J. Sadowski, 2009b. Degradation of ethofumesate in soil under laboratory conditions. Polish Journal of Environmental Studies, 18 (2): 243-247.

Kucharski, M., J. Sadowski \& K. Domaradzki, 2012. Degradation rate of chloridazon in soil as influenced by adjuvants. Journal of Plant Protection Research, 52 (1): 114-118.

Kucharski, M., J. Sadowski, B. Wujek \& J. Trajdos, 2011. Influence of adjuvants addition on lenacil residues in plant and soil. Polish Journal of Agronomy, 5: 39-42.

Lehotay, S. J., 2007. Determination of pesticide residues in foods by acetonitrile extraction and partitioning with magnesium sulfate: collaborative study. Journal of AOAC International, 90 (2): 485-520.

Lehotay, S. J., K. Mastovska \& A. R. Lightfield, 2005. Use of buffering and other means to improve results of problematic pesticides in a fast and easy method for residue analysis of fruits and vegetables. Journal of AOAC International, 88 (2): 615.

Lo, C. \& T. Lee, 2010. Effects of adjuvants on pesticide combinations: water quality on physical compatibility. Adjuvants and Agrochemicals, 32 (11): 111-119.

Miller, J. N. \& A. Ambrus, 2005. "Statistics in calibration analyses: Manual on Basic Statistics Chapter: 9: 45-49". In: Lectures Database FAO/IAEA Workshop on Introduction to QC/QA Measures in Pesticide Residue Analytical Laboratories. (12 September-7 October 2005, Seibersdorf, Vienna, Austria), 171 pp.

Okdemir, Ş., S. Öztürk \& N. Şimşir, 1965. The studies on effect of hardness of the emulsion stability Turkey waters of drugs. Plant Protection Bulletin, 5 (1): 180-190.

Park, D. \& J. C. Chong, 2010. Carrier water quality influences pesticide stability university index. Produced by PSA CAFLS Web Team Clemson University, Clemson, S.C. 29634 (864): 656-3311.

Ryckaert, B., P. Spanoghe, G. Haesaert, B. Heremans, S. Isebaert \& W. Steurbaut, 2007. Quantitative determination of the influence of adjuvants on foliar fungicide residues. Crop Protection, 26: 1589-1594.

SANTE, 2015, Guidance document on analytical quality control and method validation procedures for pesticides residues analysis in food and feed, SANTE/11945/2015.

Swarcewicz, M. K. \& A. Gregorczyk, 2012. The effects of pesticide mixtures on degradation of pendimethalin in soils. Environ Monit Assess, 184: 3077-3084.

Swarcewicz, M., A. Gregorczy \& J. Sobczak, 2013. Comparison of linuron degradation in the presence of pesticide mixtures in soil under laboratory conditions. Environ Monit Assess, 185: 8109-8114.

TUIK, 2015. Turkish Statistical Institute. (Web page: http://www.tuik.gov.tr.) (Date accessed: August 2016).

Whitford, F., 2009. The impact of water quality on pesticide performance. Purdue University Cooperative Extension Service. (Web page: hhttps://www.extension.purdue.edu/extmedia/PPP/PPP-86.pdf) (Date accessed: May 2016).

WHO, 1984. World Health Organization. Technical Report Series 699: Chemistry and Specifications of Pesticides.

Yılmaz, C. \& E. Durmuşoğlu, 2012. Changes on biological effect and degration duration of some insecticides mixed with humic matter used against Trialeurodes vaporariorum (Westw.) (Hemiptera: Aleyrodidae)] on tomato. Turkish Journal of Entomology, 36 (4): 559-571. 
